\title{
Audiodescrição fílmica no contexto da formação de tradutores
}

\section{Film Audio description for translators' training}

The best and most beautiful things in the world cannot be seen or even touched - they must be felt with the heart.

Helen Keller.

Arlene Koglin

Vitória Tassara**

\footnotetext{
" Professora Adjunta do Departamento de Letras da Universidade Federal de Pernambuco (UFPE). E-mail: arlenekoglin@yahoo.com.br

Mestranda do Programa de Pós-Graduação em Estudos da Tradução da Universidade Federal de Santa Catarina (UFSC). E-mail: vitoriatassara26@gmail.com
} 
Resumo: Este artigo analisa os desafios encontrados na aplicação prática das diretrizes de audiodescrição brasileira (MINC 2010) e norte-americanas (2007/2008) no contexto de formação de tradutores, em um curso de Bacharelado em Tradução cuja grade curricular dispunha de disciplina com módulo sobre audiodescrição. A partir de um estudo de caso, refletimos acerca do processo didático de audiodescrição do curta-metragem "Mariza". Com base no relato dos aprendizes, observamos como desafios centrais: a seleção de informação prioritária, a impossibilidade de neutralidade nas escolhas e a subjetividade de algumas diretrizes.

Palavras-chave: Audiodescrição; Formação; Diretrizes; Tradução.

Abstract: This paper analyzes the challenges found in a practical application of both the Brazilian (MINC 2010) and North American (2007/2008) audio description guidelines within the context of translators' training, on a BA Translation whose curriculum had a course with a module about audio description. Based on a case study, we have reflected upon the didactics process of audio describing the short film Mariza. From the student's reports, we have observed as main challenges: the selection of priority information, the impossibility of neutrality on the choices and the subjectivity of some guidelines.

Keywords: Audio Description; Training; Guidelines; Translation. 


\section{Introdução}

Audiodescrição (AD) é uma das modalidades de tradução audiovisual considerada como especialmente desafiadora por Gambier (2003). Destinada a pessoas cegas ou com baixa visão, esta modalidade tradutória envolve descrever linguagem corporal, ações, expressões faciais, cenários e vestimentas para que esse público possa ouvi-las juntamente com os diálogos da obra cinematográfica.

Em outras palavras, podemos definir a audiodescrição como:

[...] uma modalidade de tradução audiovisual, de natureza intersemiótica, que visa tornar uma produção audiovisual acessivel às pessoas com deficiência visual. Trata-se de uma locução adicional roteirizada que descreve as ações, a linguagem corporal, os estados emocionais, a ambientação, os figurinos e a caracterização dos personagens. (NAVES et al 2016: 10)

Embora no contexto brasileiro a audiodescrição tenha sido regulamentada somente em 2013 - como consta no Projeto de Lei № 5.156, de março de 2013, que regulamenta a profissão do audiodescritor -, em outros países a modalidade tem registros anteriores de regulamentação. $\mathrm{Na}$ Alemanha, tem-se o primeiro filme audiodescrito, em 1989, para o cinema e, em 1993, para a TV. No Reino Unido, os canais televisivos têm fornecido audiodescrição em $4 \%$ dos seus programas.

Além disso, as tecnologias decorrentes do desenvolvimento da tradução automática têm contribuído para a disseminação de produtos acessíveis a pessoas com deficiência visual. A National Dutch Public TV (NOS), por exemplo, desde 2002, tem se utilizado de tecnologias de tradução automática aliadas à conversão de texto em fala para produzir uma versão falada das legendas traduzidas automaticamente.

Diante dessa expansão e consequente necessidade de audiodescritores devidamente capacitados, é premente haver investigações sobre aspectos relacionados à formação de tais profissionais. Para tanto, este artigo propõe- 
se a refletir sobre o uso didático das diretrizes brasileira e norte-americana em termos de aplicabilidade pelo audiodescritor em formação.

A análise e discussão serão baseadas em sequência didática de natureza prática e teórica realizada na Disciplina de Tradução Audiovisual, ministrada no Curso de Bacharelado em Tradução da Universidade Federal de Pelotas no segundo semestre de 2017. A disciplina possuía um módulo da ementa dedicado à audiodescrição. Primeiramente, houve uma introdução teórica seguida de prática, a qual envolveu audiodescrição individual do curta Mariza seguida de revisão em grupo. Por fim, sob a orientação da docente, os alunos reportaram as dificuldades encontradas quanto à audiodescrição e à aplicação das diretrizes. 0 artigo está dividido em quatro seções: revisão da literatura, metodologia, análise e discussão, seguida das considerações finais.

\section{Referencial teórico}

O arcabouço teórico deste artigo engloba estudos voltados para i) o exercício da audiodescrição (AD) gravada ${ }^{1}$ de produtos audiovisuais dinâmicos de uma forma geral, ii) para a formação do audiodescritor e para iii) discussões acerca da aplicação prática da AD.

Dividimos então o capítulo do referencial teórico em três seções: uma breve exposição dos estudos de audiodescrição no Brasil e nos Estados Unidos - com o objetivo de situar as pesquisas sobre o tema -, seguido do levantamento de discussões envolvendo 0 percurso formativo do audiodescritor no Brasil e, por fim, abordaremos brevemente as diretrizes brasileiras e norte-americanas de AD.

\subsection{Os estudos de audiodescrição no Brasil e nos}

\section{Estados Unidos}

Observa-se, nas últimas décadas, uma crescente preocupação por parte de órgãos responsáveis da sociedade com a acessibilidade de pessoas com

\footnotetext{
${ }^{1}$ Audiodescrição gravada e audiodescrição ao vivo. 
algum tipo de deficiência. A audiodescrição é a ferramenta que possibilita o acesso desse grupo de indivíduos aos mais variados setores da sociedade.

A AD constitui-se uma modalidade de tradução intersemiótica - ou transmutação -, a qual é definida por Jakobson (2003) como a interpretação de signos verbais por meio de sistemas de signos não-verbais ou de um sistema de signos para outro. No âmbito do campo disciplinar dos Estudos da Tradução, a Tradução Audiovisual (TAV) é a área que engloba os estudos ligados à $A D$. Contudo, pesquisas conduzidas em outras áreas que senão os Estudos da Tradução também são notáveis e contribuem com a expansão do tema, como Costa (2014) apresenta:

As pesquisas acadêmicas sobre esse recurso de tecnologia assistiva foram iniciadas na década de 1990. A maior parte do que se produz na academia sobre o assunto vem se dando na área dos Estudos da Tradução a partir de 2000, embora a AD também seja abordada no âmbito dos Estudos da Tecnologia Assistiva e de Educação Especial (COSTA 2014: 47).

É importante mencionar que as pesquisas desenvolvidas no âmbito acadêmico têm implicações para o mercado de trabalho da mesma forma que elas são perpassadas pela trajetória dos profissionais, ou seja, há uma relação de interdependência, como apontado por Costa (2014):

A partir dos anos 2000, o número de eventos, teses, dissertações, livros e artigos têm aumentado rapidamente [sobre AD]. Vale lembrar que, ao mesmo tempo em que o avanço tecnológico propicia o surgimento de novas modalidades de tradução audiovisual, ele também é responsável por alterações nas condições de trabalho nesse meio. (COSTA 2014: 47).

Diante disso, reiteramos a importância de realizar estudos acadêmicos que integrem as reflexões teóricas em conjunto com o que está sendo feito pelos profissionais que atuam nessa área, no nosso caso da prática de $A D$.

Em consonância com a necessidade de os produtos audiovisuais apresentarem audiodescrição, o trabalho do audiodescritor e as práticas de audiodescrição são "regulamentadas" na estruturação jurídica brasileira. É possível encontrar decretos, leis e convenções que regulamentam a prática de 
audiodescrição no Brasil, dentre os quais podemos citar a Lei $n^{\circ} 13.146$ de 2015 que institui a Lei Brasileira da Pessoa com Deficiência. No tocante à audiodescrição, a partir da Lei $\mathrm{n}^{\circ} 5.156$ de 2013, que regulamenta a AD como uma modalidade de tradução, percebe-se um aumento de produções científicas e acadêmicas sobre a audiodescrição.

A preocupação do governo brasileiro nas últimas décadas com a temática da acessibilidade reflete-se diretamente nas pesquisas conduzidas no âmbito acadêmico. A partir da necessidade de produtos audiovisuais contarem com a $A D$, legenda oculta ou janela de Libras, percebe-se uma mudança de paradigmas voltados para questões de acessibilidade. No Brasil, os polos onde se concentram o maior número das pesquisas sobre essa temática são a UECE, UFMG, UFBA e UNB. (COSTA 2014).

No contexto dos Estados Unidos, é possível encontrar o registro da defesa da dissertação de Mestrado de Gregory Frazier, desenvolvida na Universidade de São Francisco, na década de 1970, e que se constituiu como um marco na história da audiodescrição no país por se tratar do registro da primeira aplicação prática de audiodescrição. Podemos encontrar informações acerca de Frazier em estudos acadêmicos, blogs e outros veículos de notícias.

Franco e Silva (2010), ao realizarem um breve passeio histórico sobre as ocorrências de pesquisas e aplicações práticas da audiodescrição, afirmam que os Estados Unidos, assim como a Inglaterra, são países pioneiros na prática de audiodescrição, devido à implementação do recurso na TV. As autoras também reiteram a importância de Frazier na história da AD no país:

Apesar de esse trabalho datar do ano de 1975, a AD teve seu debut somente na década seguinte graças ao trabalho do casal Margaret e Cody Pfanstiehl. [...] o casal, então, passou a audiodescrever as produções teatrais. Eles também foram responsáveis pelas primeiras audiodescrições em fita cassete usadas em visitas a museus, parques e monumentos nos EUA, além de contribuir de maneira significativa para levar a $A D$ à televisão. (FRANCO; SILVA 2010: 24).

Hoje, nos Estados Unidos, a partir de uma rápida busca em sites de pesquisa, é possível perceber que outros setores, além daqueles da televisão aberta, também fizeram o movimento de inserir a audiodescrição em seus 
programas, como por exemplo a Netflix ${ }^{2}$ e a Amazon Prime Video. Isso se deve ao fato de que:

Em 2010 foi assinado pelo presidente Obama, o 21st Century Communications \& Video Accessibility Act, que, entre outras coisas, obriga a exibição de quatro horas semanais de programas audiodescritos em quatro principais redes de TV aberta e cinco canais a cabo (COSTA 2014: 26).

Atualmente, no Brasil, há a obrigatoriedade de exibição de quatro horas semanais de programas audiodescritos em canais abertos. Independentemente das lacunas presentes na regulamentação da audiodescrição, e das poucas horas de obrigatoriedade, sabemos que sua aplicação em produtos audiovisuais é uma realidade em diversos países e que a parceria entre estudos conduzidos no âmbito acadêmico associada à realidade do profissional audiodescritor é vital para uma melhora na qualidade desse produto.

Após entendermos a importância da regulamentação da $A D$ em produtos audiovisuais de forma geral (tanto na TV aberta como em qualquer meio de circulação), é possível começar a refletir sobre como a audiodescrição é realizada: quem elabora o roteiro das audiodescriçõos gravadas e quem as narra? Quais os passos do processo de criação e inserção da AD nos produtos audiovisuais? O profissional responsável por tais atividades tem sua profissão regulamentada e possui treinamento e qualificação para tal? Essas reflexões nos estimulam a pensar sobre a aplicação prática da audiodescrição e de que forma isso é trabalhado em cursos de formação.

As dificuldades encontradas na aplicação prática da audiodescrição no contexto do ensino foram estudadas por Alves e Vigata (2017), os quais fazem um relato de experiência acerca da $A D$ de uma exposição artística realizada no âmbito da extensão universitária. Além destes pesquisadores, Cozendey e Costa (2018) realizam uma discussão acerca da aplicação da AD como recurso de ensino em sala de aula; Alves, Teles e Pereira (2011) apresentam sugestões para um modelo de audiodescrição e ABNT, e Seoane e Araújo (2011)

\footnotetext{
${ }^{2}$ Informação disponível em:

<https://www.nytimes.com/2018/02/05/technology/personaltech/videos-audio-

description.htm>. Acesso em: $04 \mathrm{dez} 2020$
} 
apresentam os passos metodológicos para realizar a audiodescrição de um filme brasileiro.

Além disso, na última década, testemunhamos a publicação de uma série de livros que abordam a $A D$ a partir de variados temas. Podemos citar, por exemplo, a iniciativa do governo do estado de São Paulo que lançou em 2010 e 2016, respectivamente, dois livros: "Audiodescrição: transformando imagens em palavras", organizado por Lívia Maria Villela de Mello Mota e Paulo Romeu Filho, e "Audiodescrição: práticas e reflexões”, organizado por Daiana Stockey Carpes.

Isso posto, partimos para reflexão sobre as dificuldades e possíveis estratégias ao trabalhar e ensinar a $A D$ nos cursos de formação. Portanto, passamos para a próxima seção que trata do percurso formativo dos audiodescritores no Brasil e nos Estados Unidos, que têm relação direta com a maneira como esses profissionais têm se habilitado para realizar a atividade de audiodescrição - e como podemos refletir sobre as práticas de ensino da AD.

\subsection{Breve percurso formativo do audiodescritor no Brasil e nos Estados Unidos}

Como já exposto na seção anterior, a necessidade e obrigatoriedade da audiodescrição, assim como a disseminação dos recursos acessíveis em conjunto com as tecnologias assistivas, acabou gerando uma demanda pela qualificação profissional.

No Brasil, o profissional que realiza o trabalho de audiodescrição não necessariamente se trata de um tradutor, ou de um profissional da área de Letras. Atores, intérpretes (no sentido de performers) e outros profissionais com formação variada podem vir a atuar como audiodescritores de produtos audiovisuais.

O percurso formativo desses profissionais é muito variado, assim como são os locais de oferta de cursos e o desenho curricular: desde cursos de EAD de 20 horas até os cursos de bacharelado em tradução ( 4 anos) trabalham a audiodescrição. Com relação à formação desses profissionais, Costa (2014) 
afirma que:

Os cursos de formação de audiodescritores se proliferaram desde 2008 por conta da legislação que torna obrigatório o uso da $A D$ na televisão brasileira. [...] Um dos argumentos para a diminuição do número de horas de programação audiodescrita foi a falta de profissionais formados que dessem conta da demanda crescente de AD. Diferentemente do que ocorreu na Europa, os cursos de formação aqui no Brasil são normalmente introdutórios, com duração de 20 a 60 horas, não estão ligados a pós-graduação e não necessariamente a departamentos ou cursos de tradução. (COSTA 2014: 51).

É importante ressaltar que o objetivo aqui não é fazer um levantamento de todos os cursos de formação/qualificação de audiodescrição, mas sim refletir como o percurso formativo reflete-se na aplicação prática da AD. Com relação ao aumento ou diminuição da demanda de cursos de formação, Barros e Silva (2017) discutem sobre alguns desses modelos de formação:

A demanda por cursos de formação em $A D$ também é crescente. Historicamente, o Brasil vinha utilizando dois modelos para formação em AD: treinamentos ministrados por audiodescritores com experiência de mercado ou cursos em nível de extensão universitária. Entretanto, nenhum dos modelos era considerado satisfatório. A carga horária reduzida não permitia um trabalho com a densidade e qualidade necessárias; o que levou, gradativamente, ao surgimento de cursos universitários em nível de especialização em AD. (SILVA; BARROS 2017: 164).

No Brasil, outros estudos que abordam a questão do percurso formativo dos audiodescritores, dos desenhos curriculares e da aplicação dos conhecimentos adquiridos na prática de audiodescrição são os publicados por Araújo (2010) sobre a formação de audiodescritores no Ceará e em Minas Gerais, e o de Silva e Barros (2017), que aborda a questão da formação do consultor assim como a do tradutor/audiodescritor propriamente dito.

Uma outra perspectiva é apresentada por Orero e Matamala (2008), que discutem o desenho curricular de cursos de formação em audiodescrição e as competências esperadas do profissional. A questão levantada por Orero e Matamala (2008) é se os cursos realmente preparam os profissionais para 
atuarem como audiodescritores.

Para tanto, as autoras realizam uma relação das competências desenvolvidas no aluno de tradução e dos resultados de aprendizagem do programa de Mestrado em TAV da UAB (Universidade Autônoma de Barcelona). Mostram ainda algumas das aplicações práticas que são utilizadas em sala de aula para ensinar os alunos, assim como o momento da avaliação. Esse é um dos estudos que podemos utilizar como um ponto de partida para implementar cursos de TAV - com foco na AD - aqui no Brasil. De acordo com as autoras:

O objetivo central da maioria dos cursos de acessibilidade e mídia é treinar os alunos para entender, observar e implementar a acessibilidade. Outras áreas educacionais que também tem implementado a acessibilidade audiovisual são cursos de várias áreas (Engenharia de Telecomunicações, Ciências da Computação, Jornalismo, educação, tradução) que focam em aspectos diferentes a depender dos interesses propostos (questões técnicas de conteúdo). Na Espanha, são oferecidos vários cursos relacionados à acessibilidade midiática (Badia \& Matamala, 2007), porém poucos preparam os alunos para serem audiodescritores. (ORERO; MATAMALA 2008: $5)^{3}$

Em alguns países como Alemanha, Reino Unido e Estados Unidos, no começo dos anos 2000, alguns pioneiros começam a disseminar a formação de audiodescritores. Entre eles, no contexto estadunidense, destaca-se Joel Snyder (ver SnYDER 2007; CABEZA-CÁRCERES 2013; CoSTA 2014). Conforme Costa (2014), "esses cursos de formação eram baseados nas habilidades e competências entendidas como necessárias, a partir da perspectiva de cada um desses profissionais, provenientes de suas práticas" (COSTA 2014: 50). Dessa forma, podemos deduzir que atualmente, a realidade nos Estados Unidos se assemelha com a brasileira no tocante aos contextos de formação dos audiodescritores.

Percebemos, portanto, um movimento que evidencia a preocupação

\footnotetext{
${ }^{3}$ Original: Training people to understand, observe and implement accessibility is the basic objective of most media accessibility courses. The areas of further education in which media and audiovisual accessibility have been implemented consist of courses from various fields (telecommunication engineering, computer Science, journalism, teaching, translation) which focus on different aspects depending on their interests (technical issues of content). In Spain, various courses are offered on media accessibility (Badia \& Matamala, 2007) but very few prepare students to be audio describers.
} 
com a qualificação desse profissional audiodescritor. E na tentativa de colaborar com os cursos de formação e também de proporcionar ao audiodescritor uma orientação sobre como realizar seu trabalho e aprimorar a qualidade de sua audiodescrição (e quem sabe até buscar uma padronização nos serviços de $A D$ no país), diretrizes começam a ser elaboradas. Elas são organizadas tanto por iniciativas privadas quando por ações do governo. 0 papel desses guias no processo de elaboração da audiodescrição bem como sua aplicação prática em sala de aula serão discutidos na próxima seção.

\subsection{Diretrizes brasileira e norte-americana de} Audiodescrição

A diretriz brasileira aqui analisada é o "Guia para Produções Audiovisuais Acessíveis", publicado pelo Ministério da Cultura (Secretaria do Audiovisual) em agosto de 2016. Conta com a organização de Sylvia Bahiense Naves, Carla Mauch, Soraya Ferreira Alves e Vera Lúcia Santiago Araújo. 0 Guia está disponível na internet gratuitamente e contém orientações para a elaboração de audiodescrição, de janela de Libras e de Legendagem para Surdos e Ensurdecidos, porém nosso foco será apenas na AD.

O guia está dividido em três seções: questões técnicas, questões linguísticas e questões tradutórias. Na primeira seção, são apresentadas informações sobre a inserção da $A D$ na marcação do tempo (a inserção no intervalo entre diálogos), passando pelo ritmo da narração (de acordo com o guia, "uma boa narração deve ser fluida e não monótona, sem vida” (NAVES et al, 2016, p. 11), até recomendações sobre a exibição em modelos analógicos e via software.

A segunda seção apresenta as questões linguísticas. E a terceira, questões tradutórias. São nessas duas seções que se concentram as orientações voltadas para o que audiodescrever, e de que maneira. Questões como o uso de adjetivos (o guia sugere a descrição de cores, a expressão de estados emocionais e de humor) e o uso do tempo verbal no presente do indicativo são apresentados.

As questões dos planos de enquadramento também são abordadas. 0 
Guia faz menção aos tipos de enquadramento e apresenta alguns exemplos de audiodescrição de cenas contendo os planos, por exemplo "Lentamente a imagem se aproxima do braço do homem e foca no relógio de pulso. Detalhe dos ponteiros do relógio em movimento" (NAVES et al 2016: 18).

Também são abordados temas como a tradução de atributos físicos dos personagens, dos figurinos, dos estados emocionais e dos nomes dos personagens. E um tema amplamente discutido na literatura em geral, é em qual momento revelar o nome do personagem. De acordo com o guia do Minc (2016):

Geralmente, os personagens são nomeados na $A D$ quando são nomeados na narrativa. Enquanto isso não acontece, são identificados por suas características físicas. 0 mesmo acontece para profissões ou funções. Porém, por vezes, essa conduta não ajuda na compreensão. Em situações em que esse tipo de informação, ou mesmo a relação entre os personagens fique explícita na narrativa a partir de jogos de cena, sugerese que sejam explicitadas (NAVES et al 2016: 20).

Enquanto algumas orientações do guia poderiam causar dúvidas ao aprendiz no momento de aplicá-las à prática de audiodescrição, outras diretrizes explicitam de forma mais clara o objetivo do audiodescritor na narrativa, no que diz respeito a localização dos ambientes, por exemplo:

Sugere-se audiodescrever os elementos importantes para caracterização dos ambientes de acordo com sua importância para a compreensão da obra. Por exemplo, descrever em detalhes um ambiente em que o personagem entra, fica poucos instantes, sai e não volta mais, não é relevante, e sua descrição detalhada pode desviar a atenção do foco principal. A não ser que tenha alguma função na narrativa. (NAVES et al 2016: 21).

Quanto ao vocabulário utilizado na $A D$, o guia apresenta várias colocações acerca da linguagem apropriada. Por exemplo nos trechos abaixo:

Descrever os elementos que levam o espectador a inferir o estado emocional dos personagens pode funcionar em alguns casos, [...]. Porém, é preciso evitar ambiguidades, obscuridades. Descrever um gesto ou uma expressão facial nem sempre leva ao seu entendimento, às vezes a descrição pura pode se perder no vazio. Se há tempo, recomenda-se descrever $o$ gesto e o que ele significa, principalmente levando-se em consideração as pistas visuais, senão, apenas o 
seu significado. Se um personagem coloca a mão no queixo em sinal de preocupação, pode-se descrever: "ele coloca a mão no queixo, preocupado". Ou o olhar de personagens: "Elas se entreolham com surpresa". (NAVES et al 2016: 19, grifos nossos).

Cenas de romance não podem ser descritas apenas como "o casal se beija". Como é esse beijo? Apaixonado? Rápido? Demorado? Como são as carícias? Evitar fazer uma explicação sumarizada da situação, como por exemplo: "entram no quarto e fazem amor”, ou "fazem sexo". É necessário descrever a ação à medida que ela acontece buscando as escolhas lexicais mais apropriadas. (NAVES et al 2016: 19, grifos nossos).

Como grifamos nos excertos acima, alguns trechos específicos do guia apresentam generalizações e indefinições que podem causar dúvidas ao aluno em formação ou até ao tradutor novato que for aplicar essas diretrizes na prática.

Talvez a inserção de exemplos de escolhas lexicais apropriadas, ou o fornecimento de exemplos inapropriados contrastando com o par apropriado permitiria ao audiodescritor realizar suas escolhas de maneira mais eficaz. Outra solução seria, por exemplo, a inserção de screenshots seguidos de audiodescrição apropriada e inapropriada, para demonstrar a diretriz. Há que se admitir, no entanto, que a mera utilização de guias não é suficiente para a audiodescrição, que requer outras habilidades e competências do profissional.

Considerando que os Estados Unidos são precursores na área da $A D$, optamos então por analisar o tom e o conteúdo desse guia com vistas a compará-lo com o guia brasileiro em termos de objetividade e clareza das diretrizes linguísticas e tradutórias. 0 guia, intitulado “Diretrizes para Audiodescrição e Código de Conduta Profissional para audiodescritores Baseados no Treinamento e Capacitação de Audiodescritores e Formadores dos Estados Unidos, 2007-2008"4, foi traduzido do inglês por Paulo André de Melo Vieira e está disponível na internet com acesso gratuito.

De maneira geral, o guia norte-americano apresenta-se mais completo do que o brasileiro no tocante aos contextos de audiodescrição, pois

\footnotetext{
${ }^{4}$ Disponível em:

<http://www.associadosdainclusao.com.br/enades2016/sites/all/themes/berry/documentos/12-uniaoem-prol-da-audio-descricao.pdf>. Acesso em: 07 dez 2020.
} 
apresenta informações sobre $A D$ ao vivo, de danças, de óperas e de museus, além de filmes e vídeos. Além disso, conta com o Código de Conduta do profissional e com um breve histórico da audiodescrição nos Estados Unidos.

No que diz respeito a diretrizes, aborda também a questão da censura, da etnicidade e da nacionalidade (descrever a cor da pele e a nacionalidade dos personagens), aspectos não abordados nas diretrizes brasileiras.

Por um lado, similarmente ao guia brasileiro, o guia norte-americano traz aspectos de indefinição nas orientações apresentadas, ou seja, é passível de interpretação aberta e variada, como em "descreva o que você vê" (GuIA NORTE-AMERICANO 2009: 7). Neste caso, a orientação pode levar em direção a uma descrição excessivamente detalhada, já que em algumas cenas cinematográficas, a riqueza de detalhes é constante e "o ato de se descrever o que se vê não é algo objetivo como queriam os primeiros audiodescritores" (ALVES; ARAúJo 2016: 37).

Ademais, a diretriz "descreva objetivamente, descreva o que você vê" (GUIA NORTE-AMERICANO 2009: 7) tende à contradição, pois ao mesmo tempo que carrega a subjetividade de descrever o que se vê, prescreve uma descrição objetiva, na tentativa de "atingir o ideal inalcançável do parâmetro de neutralidade" (PRAXEDEs; AraúJo; ClaUdino 2019: 37)

Por outro lado, a questão dos nomes dos personagens é similar nos dois guias. Assim como no guia brasileiro, as diretrizes norte-americanas sugerem que se "use o nome do personagem apenas quando a audiência vidente já o souber. Quando um personagem desconhecido aparecer, refira-se àquela pessoa por uma característica física usada na descrição inicial dele/dela até que o nome seja revelado". (GUIA NORTE-AMERICANO 2009: 16).

Com relação ao vocabulário, existem orientações repletas de generalizações, por exemplo: "nem todos os ouvintes entenderão gírias, coloquialismos e termos regionais. Use-os somente dentro do contexto da apresentação. Use a terminologia adequada de maneira que a maioria dos ouvintes possa entender". (GUIA NORTE-AMERICANO 2009: 13). A partir disso, uma série de reflexões se sucedem: qual é a terminologia adequada? Qual é o contexto da apresentação?

Possíveis respostas para esses questionamentos seriam a apresentação 
de uma série de escolhas terminológicas, seguindo a lógica de um corpus linguístico, que em determinados contextos audiovisuais seria mais ou menos adequada. Por exemplo, apresentar no Guia um exemplo de situação de AD diferente ( $A D$ de desenhos infantis, filmes em geral, séries de humor etc.) e em conjunto com cada contexto de apresentação, mostrar qual a terminologia mais adequada (por exemplo, a audiodescrição de um desenho infantil normalmente não apresentará a mesma terminologia do que a de uma série de humor).

Como é possível inferir do exposto anteriormente, ambos os guias trazem algumas diretrizes de cunho subjetivo, indefinido e contraditório, que podem impactar nas escolhas não só de audiodescritores, mas sobretudo gerar desafios a tradutores em formação que ainda carecem de operações cognitivas necessárias ao desdobramento adequado do processo tradutório, ou seja, de competência tradutória (ALBIR 2010).

A questão da subjetividade em guias/manuais/orientações que estabelecem diretrizes para a elaboração de $A D$ em produtos audiovisuais é criticada na literatura corrente. Bittner (2012) endossa que:

Outro problema apontado pela maioria dos estudiosos e pesquisadores da área é o fato de que essas normas [...] geralmente carecem de argumentos sólidos para embasar as regras que propõem ${ }^{5}$ (BITTNER 2012: 58).

O que podemos perceber ao realizar uma pesquisa na literatura do tema é que as diretrizes brasileiras como publicadas pelo Minc ainda carecem de fundamentos mais sólidos e concretos para serem aplicadas em sala de aula no contexto de formação de tradutores.

Alves e Teles (2017), por exemplo, nos mostram que já se tem definido qual o saber-fazer que o audiodescritor precisa desenvolver em seu percurso formativo e afirmam que:

O ADR precisa editar o que vê, ou seja, saber diferenciar o que é mais relevante, selecionar o que deve ser levado em consideração partindo do geral para o mais específico e utilizando uma linguagem objetiva, pois cabe a ele garantir

\footnotetext{
${ }^{5}$ Tradução de Silva e Barros (2017).
} 
acessibilidade, e não facilitar ou explicar a obra. (ALVES; TELES 2017: 425).

Se tomarmos as duas diretrizes discutidas aqui como base, percebe-se que o usuário não recebe informações suficientes sobre o que audiodescrever, o que é "mais importante", o que priorizar no momento da audiodescrição com limite de tempo, quais estratégias de tradução utilizar etc.

Por meio de pesquisa experimental com rastreamento ocular, Seoane (2012) compara a fixação do olhar de pessoas videntes em um curtametragem com $A D$ e o mesmo curta sem a presença da $A D$ com vistas a investigar a priorização de informações na $A D$. De acordo com os resultados encontrados por Seoane (2012):

Foi observado que mais de $77 \%$ dos elementos descritos na $A D$ do filme 'Águas de Romanza', correspondiam exatamente àqueles fixados pelos participantes do experimento. Além disso foi possível propor que os elementos que se encontram no centro da imagem, em uma cena de filme, devem ser priorizados com relação àqueles que se encontram mais afastados do centro. (SEOANE 2012: 95).

A partir de seus resultados, a pesquisadora propõe uma reflexão sobre o que priorizar no momento de audiodescrever um produto audiovisual:

Vilaró et al (2012) acreditam que a utilização do rastreador ocular com videntes assistindo a filmes com $A D$ pode qualificar um roteiro de $A D$ como bom ou ruim. Se o movimento ocular for influenciado pela $A D$ seria um indício de que o roteiro foi mal elaborado e precisa de revisão. Pois está priorizando elementos que normalmente as pessoas não priorizariam e por isso afetou o movimento ocular. (SEOANE 2012: 96).

Ao realizarmos uma rápida pesquisa nas diretrizes brasileira e norteamericana, não é possível encontrar referências a priorizar audiodescrever os elementos no centro da imagem. Como já mencionado, não há menção sobre priorização nas diretrizes abordadas aqui, há apenas algumas informações e orientações gerais, o que pode levantar a questão: “Quais elementos audiodescrever em detrimento de outros?" No que diz respeito às diretrizes, Seoane (2012) conclui em sua pesquisa que: 


\begin{abstract}
Uma nova diretriz que pode ser incluída para a priorização de informação, baseada nos estudos com rastreamento ocular, é dar prioridade para os elementos localizados no centro da imagem. Considerando que não haja outros fatores que determinem a priorização, como relevância para enredo, leitmotif ou movimento, o mais indicado seria audiodescrever o que estiver mais ao centro da imagem. Pois segundo as pesquisas de Goldstein et al (2006) e de Brasel \& Gips (2008) esta é a localização onde há a maior concentração de fixações com relação a estímulos de vídeo. (SEOANE 2012: 97).
\end{abstract}

Como descrito anteriormente, pesquisas de cunho empíricoexperimental com o público das obras audiodescritas contribuem para discutirmos como atualizar os guias e as diretrizes de Audiodescrição disponíveis atualmente. Além disso, outro público que pode se beneficiar de pesquisas dessa natureza são os profissionais envolvidos no ensino e na formação de audiodescritores. Nesse contexto, a observação das dificuldades enfrentadas pelos aprendizes pode também evidenciar eventuais necessidades de ajustes das diretrizes e de desenvolvimento de pesquisa.

Isso posto, na próxima seção descreveremos os aspectos metodológicos que dizem respeito ao relato da experiência de ensino em que as diretrizes brasileira e norte-americana foram empregadas.

\title{
3. Metodologia
}

Esta seção apresentará a descrição e a análise dos dados advindos do relato dos participantes. Inicialmente, descreverá o curta-metragem, seguido dos participantes e da sequência didática utilizada na tarefa de audiodescrição, realizada na disciplina de Tradução Audiovisual, a qual se caracterizava por dois momentos: um de discussão teórica e outro de prática de Audiodescrição (AD). Nesse contexto, após aulas expositivo-interativas sobre essa modalidade de tradução e suas diretrizes, os participantes realizaram a $A D$ de um curta-metragem.

\subsection{O curta-metragem "Mariza - O Burro Teimoso"}


O material audiovisual escolhido para ser o objeto da audiodescrição foi o curta-metragem intitulado "Mariza" e traduzido para o português brasileiro como "O Burro Teimoso"6 e para inglês como "The Stubborn Donkey". Com direção e roteiro de Constantine Krystallis, o curta tem duração de 4 minutos e não possui nenhum diálogo. A versão apresentada aos alunos foi a versão oficial, a qual traz informações e ficha técnica em inglês.

$O$ enredo se desenrola em uma ilha grega, onde um pescador (Nikos) tenta convencer sua mula (Mariza) a subir uma montanha para então vender seus peixes. Ao observar a distância da subida, a mula se recusa a andar. 0 pescador se utiliza de várias estratégias para convencê-la, e apenas obtém sucesso através de música.

Com um rádio, o pescador e a mula dançam ao longo de caminho sinuoso e íngreme e chegam ao topo da montanha, na vila, onde os peixes serão vendidos. Porém, ao chegarem ao local, o pescador percebe que todos os peixes haviam caído da cesta, devido aos movimentos de dança da mula.

Por se tratar de um curta-metragem mudo, uma de suas principais características é a alta expressividade facial dos personagens, assim como o uso de planos aproximados e em zoom. É um curta-metragem sem diálogos, que faz uso de inferências imagéticas e relações de causa e efeito.

Em função disso (e também das diretrizes utilizadas), a tarefa de audiodescrição desse curta (descrição detalhada na subseção 3.3) foi desafiadora para os tradutores em formação.

\subsection{Participantes}

Os participantes do estudo de caso relatado aqui foram os alunos do oitavo semestre do curso de Bacharelado em Tradução da Universidade Federal de Pelotas, que cursaram a disciplina de Estudos Avançados II: Tradução Audiovisual, ministrada no segundo semestre de 2017.

Seis alunos cursaram a disciplina, sendo quatro alunos do curso de bacharelado em Tradução Inglês/Português, um de Espanhol/Português e outro na categoria aluno especial.

$\mathrm{Na}$ próxima subseção, apresentaremos a sequência didática seguida

\footnotetext{
${ }^{6}$ Página oficial do site do curta-metragem: https://www.marizamovie.com/
} 
para realização da atividade de audiodescrição do curta-metragem Mariza.

\subsection{Sequência didática de audiodescrição}

A sequência didática proposta aos alunos seguiu alguns passos teóricos em constante associação com a atividade prática. Inicialmente, no passo 1, foi feita uma introdução teórica sobre a audiodescrição e seus parâmetros técnicos e linguísticos. Nesse primeiro momento também foi realizada uma discussão sobre os conhecimentos prévios sobre AD dos alunos assim como a exposição teórica e dialogada de autores/leituras sobre esse tema.

Seguiu-se, então, para a atividade prática de audiodescrição individual da obra cinematográfica (passo 2). Para produzirem suas audiodescrições, os alunos basearam-se no referencial teórico discutido previamente e em duas diretrizes: o “Guia para Produções Audiovisuais Acessíveis”, publicado em 2016 pelo Minc; e as “Diretrizes para Audiodescrição e Código de Conduta Profissional para audiodescritores Baseados no Treinamento e Capacitação de Audiodescritores e Formadores dos Estados Unidos”, publicadas entre 2007 e 2008.

Inicialmente, foram instruídos a realizarem suas audiodescrições individualmente, sempre atentando para as justificativas de suas escolhas tradutórias. Na sequência (passo 3), a docente leu as audiodescrições e destacou trechos que precisavam de ajustes.

No passo 4, os alunos foram instruídos a revisarem e a discutirem em grupo de modo a produzirem um produto final que seria então gravado. A discussão foi pautada por uma reflexão sobre os desafios de audiodescrição e de aplicação das diretrizes.

\section{Análise e discussão}

Este relato de experiência abordará alguns dos desafios experienciados pelos participantes ao audiodescreverem o curta intitulado "Mariza - The Stubborn Donkey” ou “Mariza - O Burro Teimoso". Todas as dificuldades foram 
relatadas pelos alunos durante os passos 2 e 4 da sequência didática.

O primeiro aspecto que gerou dúvidas quanto à audiodescrição foram os elementos iniciais do curta, ou seja, as informações relativas à direção e ao título. A dificuldade dos alunos se deu pelo fato de que o curta traz o nome feminino Mariza, ao passo que o site oficial do curta refere-se à trama com um pescador e um burro. Ao fim, há concordância em audiodescrever como “Um filme por Constantine Krystallis - Mariza”. O título “Mariza” é exibido antes do primeiro enquadramento do cenário (uma ilha, que é vista de longe), conforme mostrado na figura 1.

Figura 1: Imagens com nome e direção do filme exibidas antes de iniciar o curtametragem
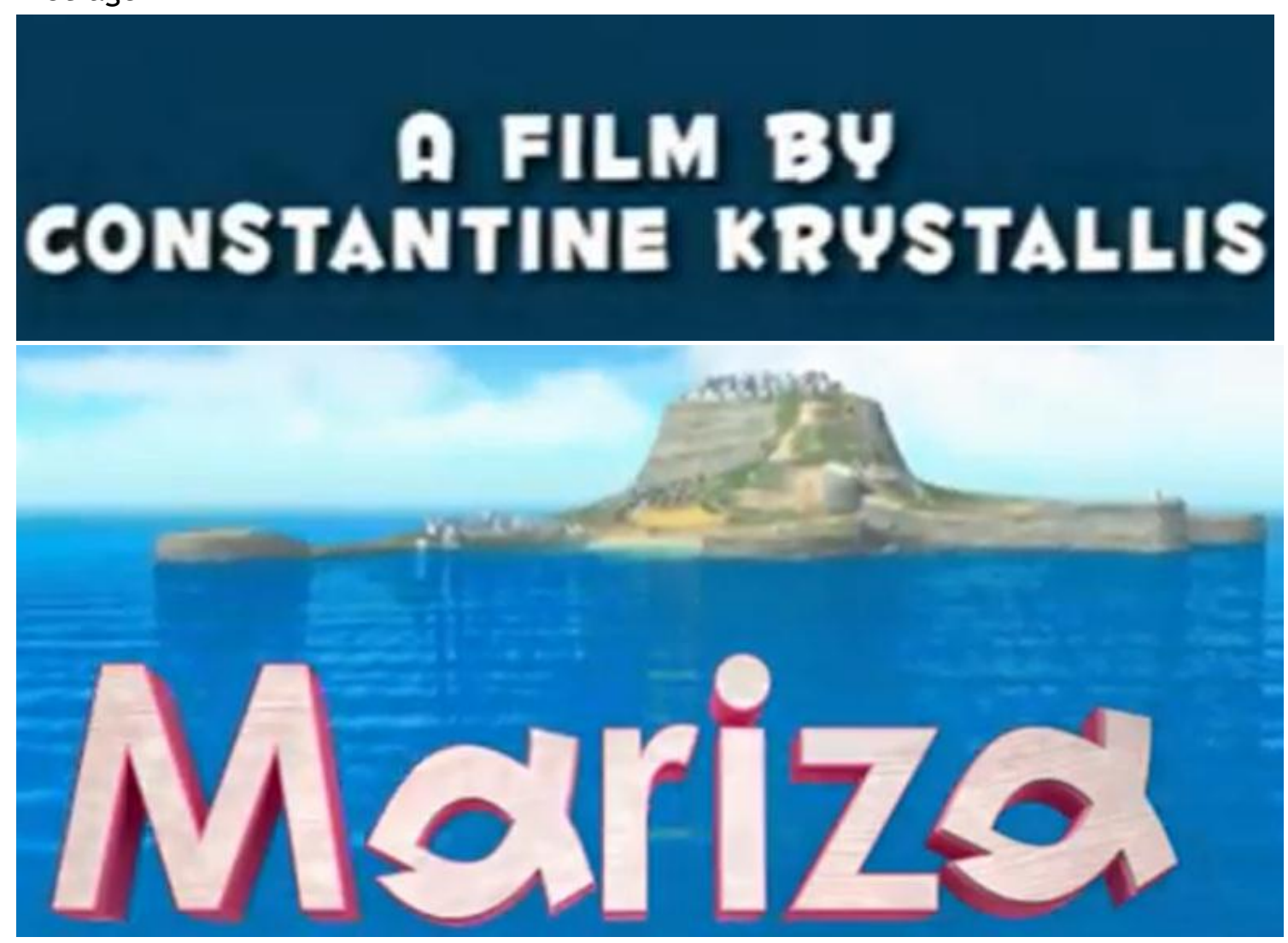

Cabe apontar que o curta oficial é intitulado apenas como Mariza, ao passo que tanto a tradução para o inglês quanto para o português brasileiro trazem adjetivos que guiam a interpretação do curta. A referência à personagem Mariza, protagonista da trama, foi traduzida para o português brasileiro como um burro teimoso.

Isso nos leva a refletir sobre as implicações de opções de tradução que apagam ou encobrem paradigmas e referências culturais. A escolha de 
tradução interlingual do título do curta nos chama atenção para a marginalização da mulher no cenário da produção colonial dominado pelo gênero masculino (SPIVAK 2010).

Outro trecho que apresenta desafios, no início do curta, é o momento em que uma ilha é focada ao longe e a imagem em movimento se aproxima gradativamente até focar em um cesto de peixes.

Figura 2: Cena inicial do filme (00:10), em que a ilha é vista à longa distância

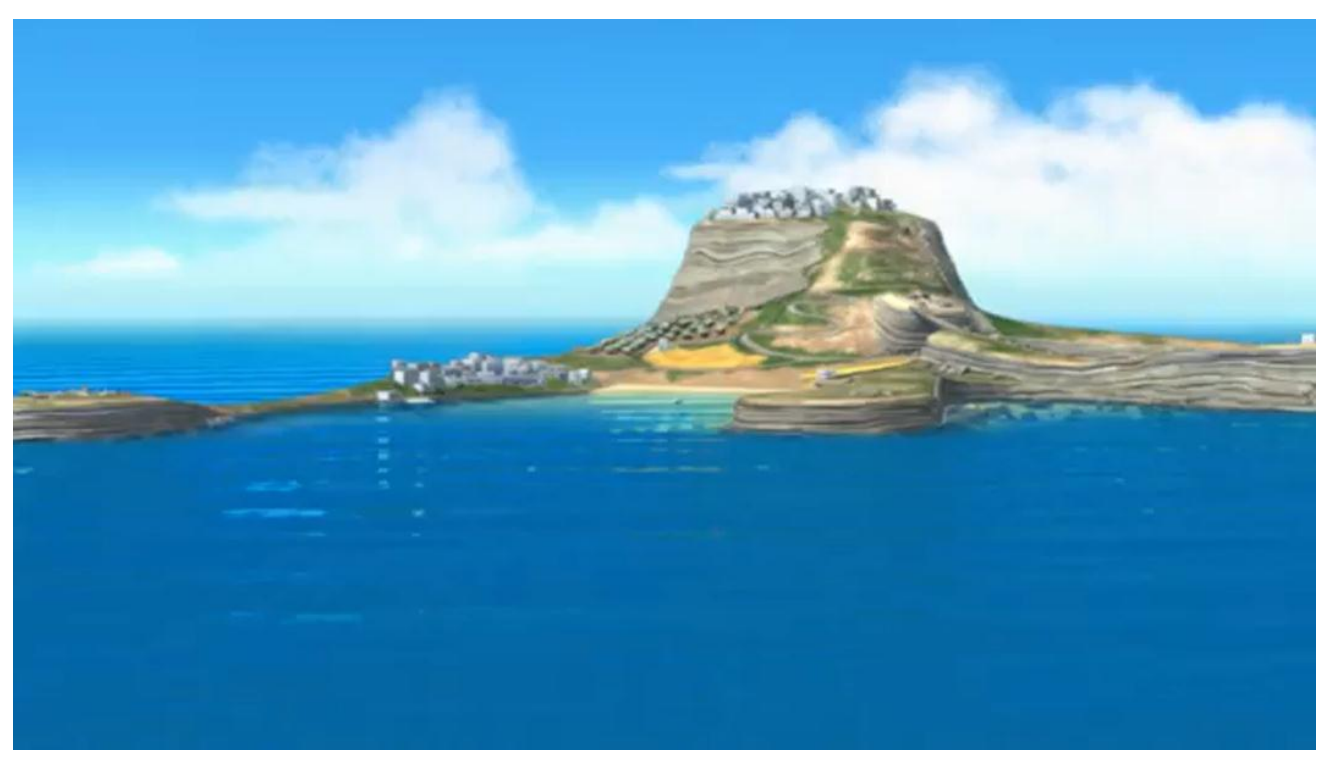

Neste caso, percebeu-se dificuldade em fazer escolhas de audiodescrição em função do tipo de plano. Esta cena inicial faz parte do grande plano geral (GPG), no qual o ambiente é mostrado de maneira ampla e é captado a longa distância e situa os personagens da trama. Embora os alunos tenham sido capazes de identificar o significado da cena dentro da narrativa, a dificuldade residiu em encontrar palavras para audiodescrever a transição de planos, do GPG para um close-up, sem causar prejuízo às inferências que deveriam ser construídas pelo espectador.

No que diz respeito ao enquadramento, o manual brasileiro traz uma descrição detalhada e de fácil compreensão quantos aos tipos de planos, porém não apresenta detalhes ou exemplos quanto ao tipo de linguagem a ser utilizada em cada caso. Para o audiodescritor em formação, que ainda não possui expertise, buscar uma solução satisfatória pode ser desafiador. Já o guia norte-americano não traz nenhuma diretriz quanto ao enquadramento na 
audiodescrição de filmes e vídeos.

Outro relato de dificuldade apontada pelos alunos foi a audiodescrição das cenas de dança. Enquanto os personagens realizavam ações importantes para a trama, o cenário também "girava" no ritmo da dança.

Figura 3: Imagens da cena em que os protagonistas (Mariza e Nikos) dançam de braços dados enquanto o cenário gira (03:19).
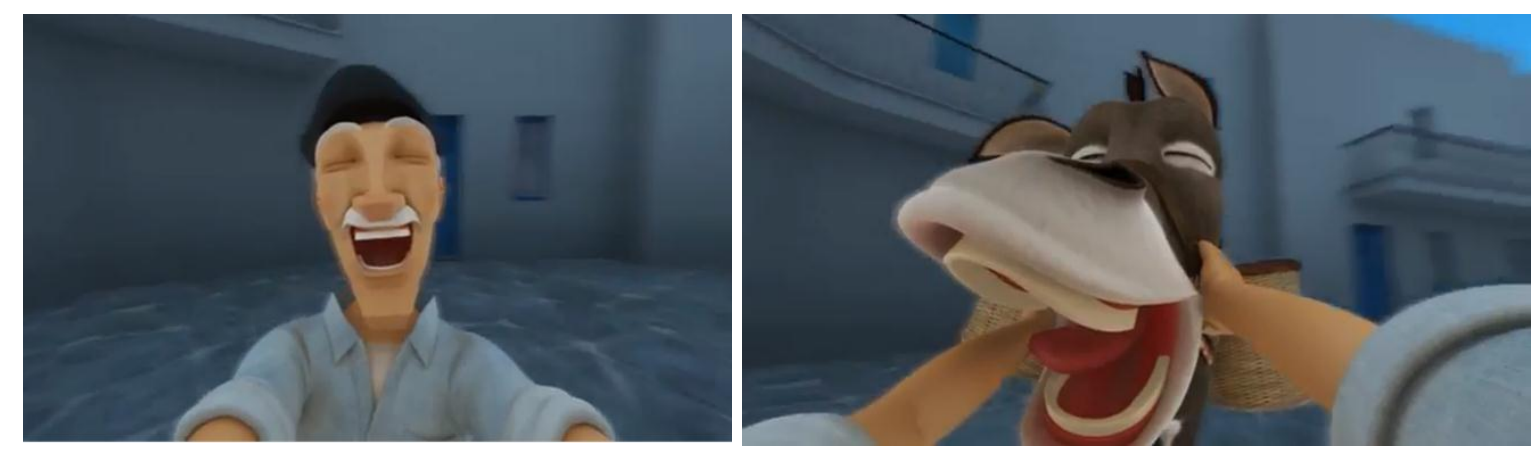

Algumas das dificuldades relatadas pelos aprendizes se pautavam na falta de orientações mais concretas em relação a emoções exprimidas por meio de expressão facial e corporal. Por se tratar de um curta-metragem sem diálogos, as expressões dos protagonistas são centrais para a realização de inferência e compreensão da trama.

No que diz respeito à descrição de emoções, o guia norte-americano não traz nenhuma orientação de como fazê-lo. Apenas se limita a apontar que os espectadores "devem ter a chance de ouvir as emoções, nas vozes dos atores e na tensão dos silêncios entre os personagens" (GUIA AMERICANO, 2009). Contudo, neste curta-metragem sem diálogos, as expressões faciais e corporais das emoções são constantes e ricas, já que possuem papel central na realização de inferências e entendimento da trama. 0 questionamento levantado pelos aprendizes foi o que deveria ser priorizado no caso desse curta-metragem: a expressão facial dos personagens que mudava rapidamente ou os elementos que os circundavam.

O guia brasileiro, embora tenha uma seção dedicada à audiodescrição dos estados emocionais e enfatize a importância de audiodescrevê-los em obras audiovisuais em que emoções sejam apresentadas de forma exacerbada, não traz instruções para este tipo específico de animação, ou seja, animações 
mudas.

Ademais, nessa cena, (figura 3) além de os estados emocionais serem ricos, há também dança, música e movimentos corporais, o que desafiou os aprendizes no sentido de identificar qual informação deveria ser priorizada. Com relação a cenas que contenham danças e/ou movimentos corporais/faciais dos personagens, pouca informação é fornecida nas duas diretrizes.

Outra cena relatada como bastante desafiadora pelos alunos não apenas durante o momento de reflexão, mas também durante a revisão em grupo, foi aquela em que a mula percebe o quão íngreme e longa é a subida até a vila localizada no topo da montanha. Em frações de segundos, sua expressão facial vai do desânimo para inquietação, susto, raiva e teimosia (ver figura 4).

Figura 4: Sequência de estados emocionais da protagonista Mariza ao perceber o caminho a ser percorrido com a carga nas costas.

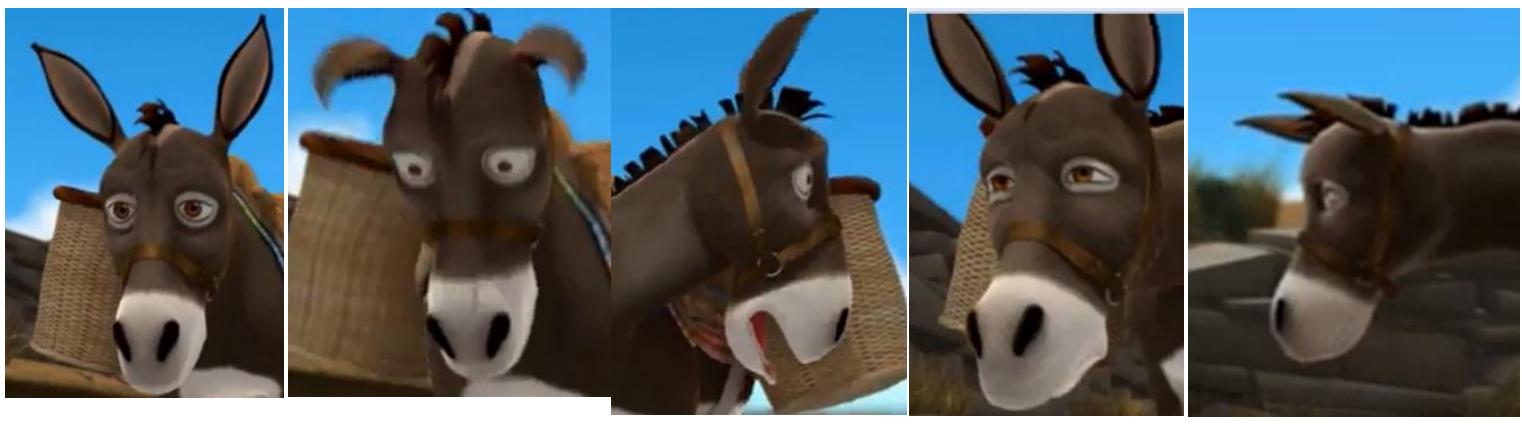

Tais estados emocionais são importantes para a compreensão da trama e realização de inferências nas cenas seguintes, em que Nikos observa que a mula parou de andar e resiste ao estímulo, dado por ele com um estalar de dedos, para continuar subindo. Além dos estados emocionais, há o enquadramento de diferentes ambientes (topo da montanha vista de baixo, placas indicando a subida além de outra vila na parte de baixo da montanha), os quais estão vinculados aos estados emocionais para a construção da narrativa.

Embora a diretriz brasileira teça algumas considerações sobre a audiodescrição do estado emocional dos personagens e apresente alguns poucos exemplos, a dificuldade dos alunos residiu em selecionar o que era 
mais importante para a compreensão e apreciação da obra. Neste caso, como se trata de um curta-metragem mudo, o enquadramento de diferentes ambientes associado ao estado emocional dos protagonistas é essencial para entendê-lo. Em função disso, faz-se necessário que o audiodescritor seja um observador ativo para compartilhar o que há nas imagens. Além das questões técnicas, linguísticas e fílmicas, é importante que o profissional aprimore seu letramento visual e olhe o mundo com maior acuidade visual (ALvES; TELES; PEREIRA 2011).

\section{Considerações finais}

Em face da escassez de pesquisas focadas na formação do audiodescritor, este trabalho propôs-se a refletir sobre os desafios encontrados durante a audiodescrição realizada por tradutores em formação. Dentre as dificuldades observadas, destacam-se a impossibilidade de usar unicamente diretrizes para audiodescrever, a necessidade de conhecimentos técnicos, linguísticos e fílmicos, além de letramento visual.

Quanto à comparação das diretrizes brasileira e norte-americana, constatamos que ambas apresentam orientações com traços de subjetividade e contradição, o que dificulta sua aplicabilidade. Enquanto o guia brasileiro apresenta uma maior variedade de exemplos para descrição de personagens e emoções, o manual norte-americano normatiza audiodescrições que busquem objetividade e neutralidade. Conforme apontam Praxedes, Araújo e Claudino (2019: 37), alguns guias "dão instruções explicitamente inviáveis; outros, contêm instruções contraditórias."

Como enfatiza Bittner (2012: 58), um problema recorrente das normas de audiodescrição é o fato de que "geralmente carecem de argumentos sólidos para embasar as regras que propõem ${ }^{7}$ ". Esta afirmação é corroborada por outros trabalhos ao realizarmos uma pesquisa na literatura sobre o tema. Afirma-se que as diretrizes brasileiras ainda carecem de fundamentos mais sólidos e concretos para serem aplicadas em sala de aula no contexto de formação de tradutores.

\footnotetext{
${ }^{7}$ Tradução de Silva e Barros (2017).
} 
Nessa direção, este relato de experiência contribuiu em apontar, de maneira mais pontual, quais são os aspectos que de fato causam desafios no contexto de formação, quais sejam: impossibilidade de objetividade na descrição, dificuldades em selecionar a informação prioritária, além da subjetividade de algumas diretrizes como "Descreva o que vê" (brasileiro) ou "Menos é mais" (norte-americano).

Por um lado, pesquisas de cunho empírico-experimental realizadas com espectadores de obras audiodescritas podem contribuir para a atualização das diretrizes, especialmente em relação à priorização da informação. Isso, por sua vez, auxiliaria tanto formadores quanto audiodescritores em formação.

Por outro lado, analisar a experiência em sala de aula com a aplicação das diretrizes amplia o entendimento não apenas em relação a pontos obscuros nas diretrizes ou de difícil aplicação na prática, como também evidencia a necessidade de pesquisas adicionais sobre as competências necessárias à formação do audiodescritor. Embora Alves e Teles (2017), por exemplo, definam que o audiodescritor necessita saber identificar o que é mais relevante, selecionar informações do âmbito geral para o mais específico, além de utilizar uma linguagem objetiva, parece-nos que ainda há carência de informação em relação à maneira mais eficaz (didaticamente) de desenvolver tais habilidades no percurso formativo dos tradutores em formação.

Ademais, há que se investigar quais são as dificuldades dos aprendizes para que, enquanto formadores de audiodescritores, possamos desenvolver sequências didáticas que os auxiliem no desenvolvimento das habilidades apontadas por Alves e Teles (2017). No âmbito didático-pedagógico, relatos de experiência, como o aqui apresentado, podem contribuir para identificação de lacunas em sequências didáticas as quais, consequentemente, afetam o aprendizado dos audiodescritores em formação. 


\section{Referências bibliográficas}

albiR, A. H. Competence. In: Gambier, Y.; Van Doorslaer, L. Handbook of Translation Studies, v. 1, Amsterdam/Philadelphia: John Benjamins Publishing Company, 2010, p. 55-59.

AlVES, S. F.; ARAÚJo, V. L. S. Formação do audiodescritor: a estética cinematográfica como base para o aprendizado da estética da audiodescrição - materiais, métodos e produtos. Cadernos de Tradução, v. 36, n. 3, p.34-26, 2016.

ALVES, S. F.; TELES, V. C. Audiodescrição Simultânea: propostas metodológicas e práticas. Trabalhos em linguística aplicada, v. 56, n. 2, p. 417-441. 2017.

Alves, S. F.; Teles, V. C; PeREIRA, T. V. Propostas para um modelo brasileiro de audiodescrição para deficientes visuais. Tradução \& Comunicação: Revista Brasileira de Tradutores, n. 22, set. 2011, p. 9-29.

AlvES, S. F.; VIGATA. H. S. A Audiodescrição na Extensão Universitária formação e prática cidadã. Domínios de Lingu@gem, v. 11, n. 5, Uberlândia, 21 dez. 2017, p. 1825-1849.

ARAÚJo, V. L. S. A Formação de Audiodescritores no Ceará e em Minas Gerais: Uma Proposta Baseada em Pesquisa Acadêmica. In: MotTA, L. M. V de M.; FILHO, P. R. Audiodescrição: Transformando Imagens em Palavras. São Paulo: Secretaria dos Direitos da Pessoa com Deficiência do Estado de São Paulo, 2010: p. 93-105.

BITTNeR, H. Audio description guidelines: a comparison. New Perspectives in Translation, v. 20, p. 41-61, 2012.

BRASIL, LEI $N^{\circ}$ 13.146, DE 6 DE JULHO DE 2015, disponível em: <http://www.planalto.gov.br/ccivil_03/_ato20152018/2015/lei//1314 6.htm>. acesso em: 25 nov 2020.

BRASIL, PROJETO DE LEI No 5.156, DE 14 DE MARÇO DE 2013, disponível em: <https://www.camara.leg.br/proposicoesWeb/fichadetramitacao?idPr oposicao $=567767>$. Acesso em: 20 nov 2020.

CABEZA-CÁRCERES, C. Audiodescripció I recipció: efecte de la velocitat de narració, l'entonació l l'explicitació en la comprensió fílimca. Barcelona, 2013, 346p. Tese (Doutorado) - Departament de Traducció I d'Interpretació, Universidade Autônoma de Barcelona, 2013.

CARPES, D. S. Audiodescrição: práticas e reflexões. Santa Cruz do Sul: Editora Catarse, 2016.

CostA, L. M. Audiodescrição em filmes: história, discussão conceitual e pesquisa de recepção. Rio de Janeiro, 2014, 401p. Tese (Doutorado) Departamento de Letras, Pontifícia Universidade Católica do Rio de Janeiro.

CozendeY, S. G.; Costa, M. da P. R da. Utilizando a tradução como um recurso de ensino. Revista Ibero-Americana de Estudos em Educação, Araraquara, v. 13, n. 03, p. 1164-1186, 2018.

Krystallis, C. Curta-Metragem Mariza. . Sydney, 2008. Disponível em: <https://www.marizamovie.com/>. Acesso em: $08 \mathrm{dez} 2020$. 
Diretrizes para Audiodescrição E Código de CONDUta Profissional para AUDIODESCRITORES BASEADOS NO TREINAMENTO E CAPACITAÇÃO DE AUDIODESCRITORES E FORMADORES DOS ESTADOS UNIDOS, 2007-2008. Trad. Paulo André de Melo Vieira.2009.

FRANCO, E. P. C.; SiLVA, M. C. C. C. da. Audiodescrição: breve passeio histórico. In: MotTA, L. M. V. de M.; FILHO, P. R. Audiodescrição: Transformando Imagens em Palavras. São Paulo: Secretaria dos Direitos da Pessoa com Deficiência do Estado de São Paulo, 2010: p. 32-42.

GAMBIER, Y. The Translator. v. 9, n. 2, p. 171-189. 2003.

JAKOBSON, R. Linguística e comunicação. $19^{\circ}$ ed. São Paulo: Cultrix, 2003 [1969] $1959 / 2003$.

Naves, S. B.; Mauch, C.; Alves, S. F.; Araújo, V. L. S. Guia para Produções Audiovisuais Acessíveis, Ministério da Cultura (Minc), 2016.

Orero, P.; Matamala, A. Designing a course on Audio Description and Defining the Main Competences of the Future Professional. Universitat Autònoma de Barcelona. 2008.

Praxedes Filho, P. H. L.; Araújo, V. L. S.; Claudino, K. de A. Avaliação de roteiros de audiodescrição. Letras \& Letras, v. 35, n. 2, p. 34-61, 2019.

SEOANE, A. F. A priorização de informações em roteiros de audiodescrição: $o$ que o rastreamento ocular tem a nos dizer? $114 \mathrm{f}$. Dissertação (Mestrado) - Programa de Pós-Graduação em Linguística Aplicada. Universidade Estadual do Ceará, Fortaleza, 2012.

SeOANE, A. F.; ARAúJo, V. L. S. Elaboração e análise da audiodescrição do filme Corisco e Dadá. Cultura \& Tradução, João Pessoa, v. 1, n. 1, 2011, pp. 1-10.

SILVA, M. da; BARROS, A. Formação de audiodescritores consultores: inclusão e acessibilidade de ponta a ponta. Revista FAEEBA - Ed. e Contemp.; Salvador, v. 26, n. 50, pp. 159-170, 2017.

SpIVAK, G. C. Pode o subalterno falar? 1. Ed. Trad. Sandra Regina Goulart Almeida; Marcos Pereira Feitosa; André Pereira. Belo Horizonte: Editora da UFMG, 2010.

Recebido em: 16/04/2020

Aceito em: $16 / 11 / 2020$

Publicado em dezembro de 2020 